\title{
Kinetic Evidence for Hypervalent Intermediate in Acid Hydrolysis of $\mathrm{N}$-Arylbenzenesulfinamides
}

\author{
Jong Pal Lee, Woo Roi Kim, Yong Hee Lee, ${ }^{\dagger}$ and In Sun Koo* \\ Department of Chemistry, Dong-A University, Busan 604-714, Korea. *E-mail: jplee@dau.ac.kr \\ ${ }^{\dagger}$ Research Institute for Basic Sciences, Dongeui University, Busan 614-714, Korea \\ ${ }^{\ddagger}$ Department of Chemistry Education and Research Institute of Natural Science, \\ Gyeongsang National University, Jinju 600-701, Korea \\ Received February 28, 2006
}

Key Words : Hypervalent intermediate, Sulfinamide, Basicity, Protonation

Nucleophilic substitution reactions of sulfinic acid derivatives occur with predominent inversion of configuration at sulfur. ${ }^{1}$ These results are mainly interpreted by an addition elimination mechanism with a trigonal bipyramidal reaction intermediate (sulfurane) and a concerted $\mathrm{S}_{N} 2$ displacement mechanism. ${ }^{1,2}$

The isolation of stabilized bicyclic sulfurances suggests that these species may form as intermediates in nucleophilic substitution reactions of sulfinic acid derivatives. ${ }^{3}$ However, despite continuing efforts, there are very rare definitive experiments to demonstrate the formation of these intermediates.

Some years ago, ${ }^{4}$ we reported acid catalyzed hydrolysis of some simple sulfinamides. In this report, we found downward breaks in the $\mathrm{pH}$-rate profile for acid catalyzed hydrolysis of sulfinamides having electron donating group in the leaving group, aniline. These data provided the first unequivocal evidence that nucleophilic substitution reaction at sulfinyl sulfur may proceed by a two-step mechanism through a hypervalent reaction intermediate.

In this study, we have extended our study to identify the hypervalent intermediate in acid catalyzed reactions of sulfinamides having halide or more stronger electron donating group in the leaving group or the sulfinyl group. So, we have performed the acid catalyzed hydrolyses of $\mathrm{N}$-(3methyl-5-methoxyphenyl)-benzenesulfinamide (1-a), $\mathrm{N}$ (tolyl)-toluenesulfinamide (1-b), $\mathrm{N}$-(4-fluorophenyl)-toluenesulfinamide (1-c), $N$-(4-ethylphenyl)-benzenesulfinamide (1-d) and $N$-(4-fluorophenyl)-benzenesulfinamide (1-e).

\section{Experimental Section}

Materials. All materials and solvents for synthesis of the substrates were purchased from Aldrich or Tokyo Kasei. Acid solution were prepared from concentrated acid $(60 \%$ $\left.\mathrm{HClO}_{4}\right)$ and titrated with standard $\mathrm{NaOH}$ solution. Water used for acidic solutions was freed from $\mathrm{CO}_{2}$ by boiling deionized water under a nitrogen gas. All organic solvents were purified by the well known methods. ${ }^{5}$

$N$-arylbezenesulfinamides were prepared by addition of sulfinyl chloride to appropriate amines as previously described. ${ }^{6}$ Benzenesulfinyl chloride was obtained by purging chlorine gas to reaction mixtures of $0.1 \mathrm{~mol}$ diphenyldisulfide and $0.2 \mathrm{~mol}$ acetic anhydride at $0{ }^{\circ} \mathrm{C} \sim-10{ }^{\circ} \mathrm{C}$. Byproducts, acetylchloride and excess chlorine were removed by heating to $50{ }^{\circ} \mathrm{C}$ under reduced pressure $(15 \mathrm{mmHg})$. $\mathrm{N}$-arylbezenesulfinamides synthesized were purified by the method of either a silica gel column chloromatography or recrystallization and identified by spectral data as follows.

$\mathrm{N}$-(3-Methyl-5-methoxyphenyl)-benzenesulfinamide (1-a): pale green solid; m.p. 89-91 ${ }^{\circ} \mathrm{C}$; $\mathrm{Rf}=0.1$ (hexane/ethylacetate/2/1); FT-IR $\left(\mathrm{KBr}, \mathrm{cm}^{-1}\right), 3438(\mathrm{~N}-\mathrm{H}), 1305(\mathrm{~S}=\mathrm{O})$; ${ }^{1} \mathrm{H}$ NMR $\left(200 \mathrm{MHz}, \mathrm{CDCl}_{3}\right), \delta 2.27(\mathrm{~s}, 3 \mathrm{H}), 3.77(\mathrm{~s}, 3 \mathrm{H})$, $5.89(\mathrm{~s}, 1 \mathrm{H}), 6.56(\mathrm{~d}, 1 \mathrm{H}), 6.93(\mathrm{~s}, 1 \mathrm{H}), 7.03(\mathrm{~d}, 1 \mathrm{H}), 7.56-$ 7.40 (m, 3H), 7.69-7.71 (m, 2H); Mass (m/z), $259\left(\mathrm{M}^{+}\right)$.

$\mathrm{N}$-(Tolyl)-toluenesulfinamide (1-b): white solid (recrystallization from ether); m.p. $117-119^{\circ} \mathrm{C}$ (lit., ${ }^{7} 118-120$ $\left.{ }^{\circ} \mathrm{C}\right)$; Mass $(\mathrm{m} / \mathrm{z}), 245\left(\mathrm{M}^{+}\right)$.

$\mathrm{N}$-(4-Fluorophenyl)-toluenesulfinamide (1-c): yellow solid; m.p. $115-117{ }^{\circ} \mathrm{C}$; $\mathrm{Rf}=0.4$ (hexane/ethylacetate/2/1); FT-IR (KBr, cm $\left.{ }^{-1}\right), 3220(\mathrm{~N}-\mathrm{H}), 1325(\mathrm{~S}=\mathrm{O}) ;{ }^{1} \mathrm{H}$ NMR $(200$ $\left.\mathrm{MHz}, \mathrm{CDCl}_{3}\right), \delta 2.43(\mathrm{~s}, 3 \mathrm{H}), 5.90(\mathrm{~s}, 1 \mathrm{H}), 6.93-6.97(\mathrm{~m}$, 2H), 7.02-7.06 (m, 2H), 7.31-7.35 (m, 2H), 7.36-7.67 (m, $2 \mathrm{H})$; Mass (m/z): $249\left(\mathrm{M}^{+}\right)$.

$\mathrm{N}$-(4-Ethylphenyl)-benzenesulfinamide (1-d): pale yellow solid; m.p. $116-118{ }^{\circ} \mathrm{C}$; $\mathrm{Rf}=0.5$ (hexane/ethylacetate/2/1); FT-IR (KBr, cm $\left.{ }^{-1}\right), 3434(\mathrm{~N}-\mathrm{H}), 1290(\mathrm{~S}=\mathrm{O})$; ${ }^{1} \mathrm{H} \mathrm{NMR}\left(200 \mathrm{MHz}, \mathrm{CDCl}_{3}\right), \delta 1.19(\mathrm{t}, J=4.3,3 \mathrm{H}), 2.60(\mathrm{q}$, $J=7.5,2 \mathrm{H}), 6.21(\mathrm{~s}, 1 \mathrm{H}), 7.05-7.10(\mathrm{~m}, 2 \mathrm{H}), 7.30-7.33$ (m, 3H), 7.52-7.56 (m, 2H), 7.71-7.76 (m, 2H); Mass (m/z), 245 $\left(\mathrm{M}^{+}\right)$.

$\mathrm{N}$-(4-Fluorophenyl)-benzenesulfinamide (1-e): brown solid; m.p. $103-105{ }^{\circ} \mathrm{C}$; $\mathrm{Rf}=0.4$ (hexane/ethylacetate/2/1); FT-IR $\left(\mathrm{KBr}, \mathrm{cm}^{-1}\right), 3446(\mathrm{~N}-\mathrm{H}), 1375(\mathrm{~S}=\mathrm{O}) ;{ }^{1} \mathrm{H}$ NMR $(200$ $\left.\mathrm{MHz}, \mathrm{CDCl}_{3}\right), \delta 6.02(\mathrm{~s}, 1 \mathrm{H}), 6.97-7.01(\mathrm{~m}, 2 \mathrm{H}), 7.02-7.05$ $(\mathrm{m}, 2 \mathrm{H}), 7.52-7.55(\mathrm{~m}, 3 \mathrm{H}), 7.75-7.77(\mathrm{~m}, 2 \mathrm{H})$; Mass $(\mathrm{m} / \mathrm{z})$, $234\left(\mathrm{M}^{+}-\mathrm{H}\right)$.

Kinetics. The rates for acid catalyzed hydrolysis were measured spectrophotometerically in aqueous perchloric acid at the constant ionic strength of $0.1 \mathrm{M}$ with $\mathrm{NaClO}_{4}$ in the concentration range from $5.0 \times 10^{-2}$ to $1.0 \times 10^{-4} \mathrm{~mol}$ $\mathrm{dm}^{-3}$ at $25 \pm 0.1^{\circ} \mathrm{C}$ by following the decrease in absorbance due to disappearance of the substrates at wavelengths in the range of 246-254 $\mathrm{nm}$. 
Table 1. Catalytic rate constants for acid catalyzed hydrolysis of the various $N$-arylbenzenesulfinamides $\left(\mathrm{XC}_{6} \mathrm{H}_{4} \mathrm{~S}(\mathrm{O}) \mathrm{NHAr}\right)$ at 25 ${ }^{\circ} \mathrm{C}$ and ionic strength $0.1 \mathrm{M}$ with $\mathrm{NaClO}_{4}$

\begin{tabular}{cccccc}
\hline \multicolumn{3}{c}{ Substrates } & & \multicolumn{2}{c}{$k_{\mathrm{H}}\left(\mathrm{M}^{-1} \mathrm{~s}^{-1}\right)$} \\
\cline { 1 - 2 } \cline { 5 - 6 } No. & $\mathrm{X}$ & $\mathrm{Ar}$ & $\mathrm{pH}>3$ & $\mathrm{pH}<3$ \\
\hline 1-a & $\mathrm{H}$ & $2-\mathrm{CH}_{3}, 5-\mathrm{CH}_{3} \mathrm{OC}_{6} \mathrm{H}_{3}$ & & 2.77 & 1.84 \\
& & & $(\mathrm{r}=0.9962)$ & $(\mathrm{r}=0.9996)$ \\
1-b & $p-\mathrm{CH}_{3}$ & $p-\mathrm{CH}_{3} \mathrm{C}_{6} \mathrm{H}_{4}$ & & 1.49 & 0.712 \\
& & & $(\mathrm{r}=0.9994)$ & $(\mathrm{r}=0.9988)$ \\
1-c & $p-\mathrm{CH}_{3}$ & $p-\mathrm{FC}_{6} \mathrm{H}_{4}$ & & 3.33 & 1.63 \\
& & & $(\mathrm{r}=0.9965)$ & $(\mathrm{r}=0.9969)$ \\
1-d & $\mathrm{H}$ & $p-\mathrm{C}_{2} \mathrm{H}_{5} \mathrm{C}_{6} \mathrm{H}_{4}$ & & $1.29^{a}$ \\
& & & $(\mathrm{r}=0.9992)$ \\
1-e & $\mathrm{H}$ & $p-\mathrm{FC}_{6} \mathrm{H}_{4}$ & & $0.958^{a}$ \\
& & & $(\mathrm{r}=0.9994)$ \\
\hline
\end{tabular}

${ }^{a}$ The values were calculated at the whole $\mathrm{pH}$ range $(\mathrm{pH} 1.3-4.0)$. Standard deviations of all $k_{\mathrm{H}}$ values are between $9.29 \times 10^{-3}$ and $4.25 \times$ $10^{-2}$.

The rate measurements were carried out using a Hewlett Packard 8452 Diode Array Spectrophotometer equipped with a Shimadzu TB- 85 thermo bath to keep the temperature of the reaction mixture at $25^{\circ} \mathrm{C} \pm 0.1^{\circ} \mathrm{C}$. Typically, kinetic run was initiated by injecting $30 \mu \mathrm{L}$ of $1.0 \times 10^{-2} \mathrm{M}$ stock solution of the substrate dissolving in acetonitrile into 3.0 $\mathrm{mL}$ of aqueous perchloric acid solution.

The catalytic rate constants were obtained from plot of rate constant versus concentration of acid. $\mathrm{pH}$ values of reaction mixtures were measured at $25^{\circ} \mathrm{C}$ with a DP-215M Dong-Woo meter.

\section{Results and Discussion}

The acid catalyzed hydrolysis reactions were carried out under pseudo first order conditions. The observed rate constants $\left(k_{o b s}\right)$ were obtained from $89532 \mathrm{~K}$ Kinetic Software (serial No. 325 G00380) of the Hewlett Packard company which was based on the slope value of the plot of $\ln \left(A_{0}-A_{t}\right)$ vs. time. The observed rate constants for the acid



Figure 1. pH-rate profiles for acid catalyzed hydrolyses of $N$ (tolyl)-toluenesulfinamide (1-b: - ) and $N$-(4-fluorophenyl)benzenesulfinamide (1-e: $\boldsymbol{\square})$ at $25^{\circ} \mathrm{C}$ and the ionic strength of 0.1 $\mathrm{M}$ with $\mathrm{NaClO}_{4}$.

catalyzed reaction of all compounds are proportional to acid concentration with a slope of -1.0 in the $\mathrm{pH}$ range 1.3-4.0. Therefore, the observed rate constant $\left(k_{o b s}\right)$ is given by equation (1), where $k_{\mathrm{H}}$ is the catalytic rate constant of hydronium ion.

$$
k_{o b s}=k_{\mathrm{H}}\left[\mathrm{H}_{3} \mathrm{O}^{+}\right]
$$

The catalytic rate constants are listed in Table and the $\mathrm{pH}-$ rate profiles are presented in Figure.

The $\mathrm{pH}$ rate profile of the compound (1-e) shows a straight line with increasing concentration of acid, while that for the substrate (1-b) having electron donating group in benzenesulfinyl group and leaving group appears a break at around $\mathrm{pH}$ 3.0. A similar break was also observed for the substrates (1-a) and (1-c) but not for the substrate (1-d).

These results are accommodated with reaction mechanism

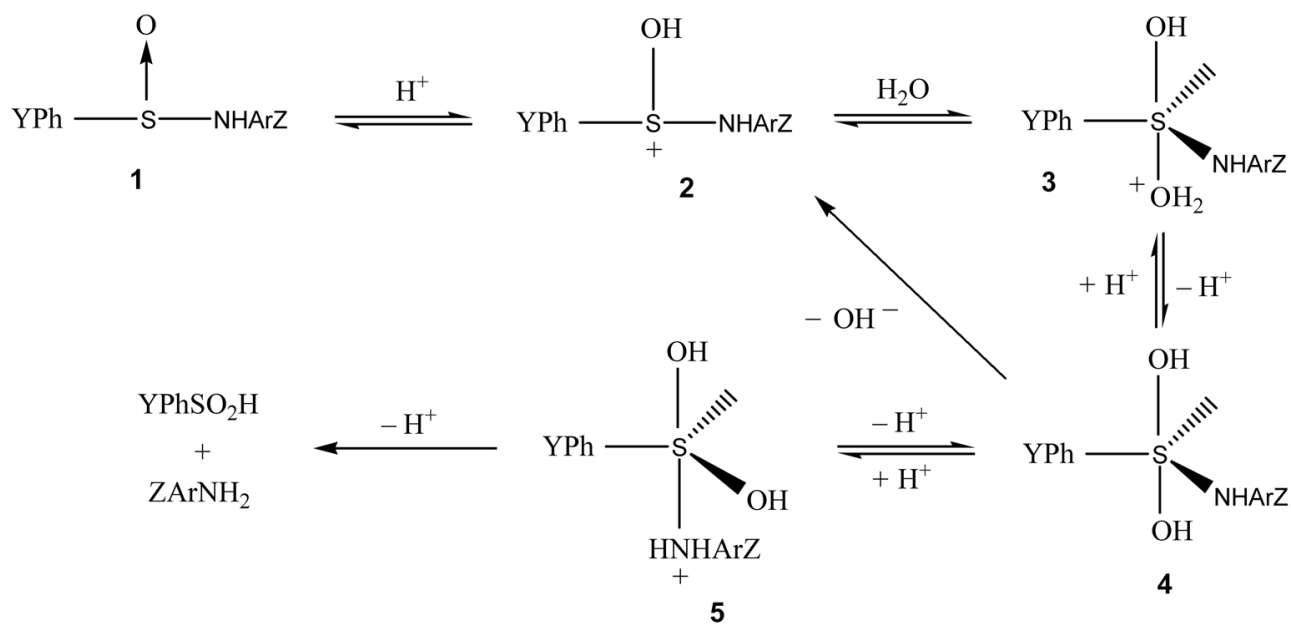

Scheme 1 
involving hypervalent intermediates as shown in Scheme 1; i.e., a change over of the rate determining step occurs at around $\mathrm{pH} 3$ for the substrates (1-a), (1-b) and (1-c). In Scheme 1, the first protonation to the substrate occurs at sulfinyl oxygen atom from the previous observation for which the substrate undergoes ${ }^{18} \mathrm{O}$ isotope exchange during hydrolysis. ${ }^{4}$ And then, the intermediates are in various forms of configuration and of protonation. Among the protonated forms, 3 returns to the reactant, 2 by giving away $\mathrm{H}_{2} \mathrm{O}$, while the $N$-protonated form, $\mathbf{5}$ goes to the product by expelling aniline.

In the hydrolyses of (1-a), (1-b) and (1-c), the rate determining step at the lower $\mathrm{pH}$ should be the formation of the intermediate, since the greater fraction of the protonated intermediate is in the form of $\mathbf{5}$ because of higher basicity of the amine fraction as compared with the case of the substrates, (1-d) and (1-e), having ethyl and fluoro substituents and thus the decay of the intermediate is more facilitated. ${ }^{4}$

With increasing $\mathrm{pH}$, the contribution from the neutral intermediate 4, which returns to the reactant form, becomes greater and the decay of the intermediate becomes rate determining step. In the case of the substrates (1-d) and (1-e) having less basic aniline group, the contribution from $\mathbf{5}$ is smaller and then the rate determining step must be the decay of the intermediate in the whole $\mathrm{pH}$ range.
Finally, a significant aspect of this study is to observe kinetic evidence for the hypervalent intermediate in acid hydrolysis of sulfinamides having more stronger electron donating group in the sulfinyl group or in the leaving group.

Acknowledgment. This paper was supported by the Dong-A University Research fund in 2005.

\section{References}

1. 1. (a) Mikolajczyk, M.; Drabowicz, J. Top. Stereochem. 1982, 13, 333. (b) Mikolajczyk, M. Phosphorus Sulfur 1986, 27, 31. (c) Mikolajczyk, M. In Organic Sulfur Chemistry; Zwanenburg, B., Klunder, A. J. H., Eds.; Elsevier: Amsterdam, 1987; pp 23-40. (d) Okuyama, T. In The Chemistry of Sulphinic Acids, Ester and Their Derivatives; Patai, S., Ed.; Wiley: Chichester, 1990; pp 623-637.

2. (a) Oh, H. K.; Park, J. E.; Lee, H. W. Bull. Korean Chem. Soc. 2004, 25, 1041. (b) Oh, H. K.; Lee, J. M. Bull. Korean Chem. Soc. 2004, 25, 203

3. Perkins, C. W.; Wilson, S. R.; Martin, J. C. J. Am. Chem. Soc. 1985, 107, 3209 .

4. Okuyama, T.; Lee, J. P.; Ohnishi, K. J. J. Am. Chem. Soc. 1994, 116,6480 .

5. Riddick, J. H.; Bunger, W. B. Organic Solvents, 4th ed.; John Wiley \& Sons, Inc.: 1970; p 594, 694, 749, 798.

6. (a) Furukawa, M.; Okuyama, T. Synthesis 1976, 339. (b) Lee, J. P.; Uhm, T. S. J. Korean Chem. Soc. 1997, 41(1), 39.

7. Mori, K.; Ueda, Y. Yakugaku Zasshi 1971, 91, 941. 